\title{
Identification of microorganisms in upper endoscopy of patients with different gastrointestinal diseases
}

\author{
Khadiga Ahmed Ismail ${ }^{1,2 *}$, Howaida Mahmoud Rezk ${ }^{1,2}$, Mona Mutlaq AlOtabi ${ }^{1,2}$, Wedad Said Elthabati ${ }^{1,2}$ and Ahmed Mahmoud Khalifa ${ }^{3}$ \\ ${ }^{1}$ Laboratory Medicine Department, College of Applied Medical Sciences, Taif University, Taif, Saudi Arabia \\ ${ }^{2}$ Parasitology Department Faculty of Medicine, Ain-Shams University, Cairo, Egypt \\ ${ }^{3}$ Forensic and Toxocology Department Faculty of Medicine, Ain-Shams University, Cairo, Egypt
}

\begin{abstract}
The microbiota of the human stomach and its composition remain largely unknown endoscopic biopsy samples show a diverse community of many phylotypes which was identified, our study is carried on 21 patients submitted to upper gastrointestinal endoscopic examination the majority of microorganisms were Gram +ve cocci $52 \%$ (Kocuria kristina, Staph hyicus and Staph sciuri, staph intermiduis). Gram -ve bacilli were 5\% and Giardia were $10 \%$ but $33 \%$ of cases have no growth. The relation between microorganisms in upper gastrointestinal tract endoscopy and its relation with the endoscopic finding showed that microorganisms increased with erosive gastritis and gastropathy, direct relation between bacterial growth in gastric wash and proton pump inhibitor drug intake with higher frequency of increased bacterial growth with proton pump inhibitor drug intake, but there is inverse relation between Helicobacter growth with proton pump intake (PPI) intake as there is higher growth with non PPI intake and this may result from patchy bacterial colonization through the stomach and altered distribution because of gastritis with atrophy. So multiple gastric biopsies were recommended from different sites.
\end{abstract}

\section{Introduction}

Routine diagnostic upper gastrointestinal endoscopy is the standard practice for diagnosing esophageal, gastric and duodenal diseases. It has very low complication and mortality rates [1].

Gastritis is an inflammatory condition of gastric mucosa that displays change related to etiology and the host response. Gastritis is an infectious or auto-immunological inflammation [2]. Gastritis may be acute or chronic, sudden severe inflammation of the stomach lining is called acute gastritis. Inflammation that lasts for a long time is called chronic gastritis. If chronic gastritis is not treated, it may last for years or even a lifetime [3]. Chronic gastritis was categorized into two subgroups: namely, superficial and atrophic [2].

The most common cause of erosive gastritis-acute and chronic-is prolonged use of nonsteroidal anti-inflammatory drugs (NSAIDs) such as aspirin and ibuprofen. Other agents that can cause erosive gastritis include alcohol, cocaine, and radiation. Traumatic injuries, critical illness, severe burns, and major surgery can also cause acute erosive gastritis. This type of gastritis is called stress gastritis. Helicobacter pylori (H. pylori) infection causes most cases of chronic nonerosive gastritis. H. pylori are bacteria that infect the stomach lining [4].

Helicobacter pylori (H. pylori) infection has a worldwide distribution and is causally associated with chronic gastritis, peptic ulcer disease, gastric cancer and mucosal associated lymphoid tissue (MALT) lymphoma [5].

Fifty percent of the world's population is infected with $\mathrm{H}$. pylori. This rate is $70 \%$ in developing countries [2], meaning that its prevalence is low in developed countries and relatively high in developing countries where the infection occurs early in life and is often associated with low socio-economic status [6]. Peptic ulcer disease and gastric carcinoma are common in the Kingdom of Saudi Arabia (KSA) and as in many populations, they account for major health care cost and significant economic loss from absenteeism, morbidity and deaths from complications $[7,8]$.

The increased prevalence of infection with age was initially thought to represent a continuing rate of bacterial acquisition throughout one's lifetime. However, epidemiologic evidence now indicates most infections are acquired during childhood even in developed countries. Most infections were acquired before five years of age [9].

The consumption of salted food appears to increase the possibility of persistent infection with $H$. pylori infection [10]. In addition, a synergistic interaction between $H$. pylori infection and salted food intake to increase the risk of gastric cancer has also been reported in case-control studies [11,12].

Most forms of chronic nonspecific gastritis do not cause symptoms. However, chronic gastritis is a risk factor for peptic ulcer disease, gastric polyps, and benign and malignant gastric tumors. Some people with chronic H. pylori gastritis or autoimmune gastritis develop atrophic gastritis. Atrophic gastritis destroys the cells in the stomach lining that produce digestive acids and enzymes. Atrophic gastritis can lead to two types of cancer: gastric cancer and gastric mucosa-associated lymphoid tissue (MALT) lymphoma [2]. The objective of this study is

Correspondence to: Khadiga Ahmed Ismail, Laboratory Medicine Department, College of Applied Medical Sciences, Taif University, Taif, Saudi Arabia, E-mail: khadigaahmed68@yahoo.com

Key words: microorganisms, upper gastrointestinal endoscopy, gastrointestinal diseases

Received: November 20, 2017; Accepted: December 08, 2017; Published: December 12, 2017 
to identify microorganisms in upper gastointestinal tract endoscopy and its relationship with the endoscopic finding.

\section{Material and method}

Cross section study was applied and the samples from endoscopic clinic including gastric wash were withdrawn in normal salina also gastric endoscopic biopsies were withdrawn in formalin $10 \%$, the samples were transferred to departments of microbiology and histopathology and submitted to the following steps:

\section{1) Gram stain}

Gram staining is a common technique used to differentiate two large groups of bacteria based on their different cell wall constituents.

\section{2) Culture the samples on}

blood agar, macConky agar and chochalate and another plate blood agar for anaerobic bacteria such as clostridium genus and incubated for 48 hours

\section{3)The microscan WalkAway-96}

WalkAway-96 instrument is an automated system which incubates microtiter identification and antimicrobial susceptibility testing panels, interprets biochemical results using a photometric or fluorogenic reader, and generates computerized reports.

\section{4) Hematoxylin and eosin histological technique}

The biopsy specimens that were fixed in $10 \%$ buffered neutral formalin were processed in automatic tissue processor for paraffin embedding, and then 3-5 $\mu$ sections were cut. The sections were stained with hematoxylin and eosin ( $\mathrm{H}$ and $\mathrm{E}$ ) for evaluation of histopathological features as (presence and severity of gastritis, lymphoid follicles hyperplasia, erosions and atrophy and special stains such as Giemsa used to detect H. pylori organisms.

\section{Result}

Study conducted on 21 patients their mean age is $40.1 \pm$ SD. 14.1 (Figures 1-9 and Table 1).

\section{Discussion}

The microbiota of the human stomach and its composition remain largely unknown. A diverse community of 128 phylotypes was identified in endoscopic biopsy samples. The majority of microorganisms were assigned to the, Bacteroidetes, and Fusobacteria phyla. The normal stomach of a healthy volunteer is usually sterile without any bacterial growth in the fasting secretion [13].

Except for a few hours immediately following a meal, the human stomach is largely devoid of a significant microbiota in healthy people,

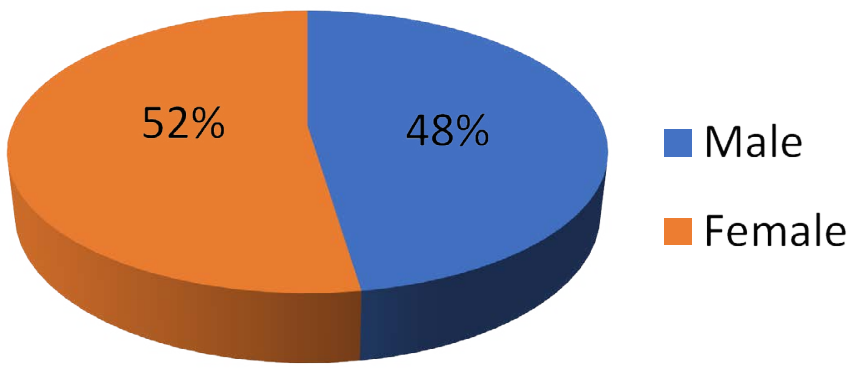

Figure 1. Show male and female distribution

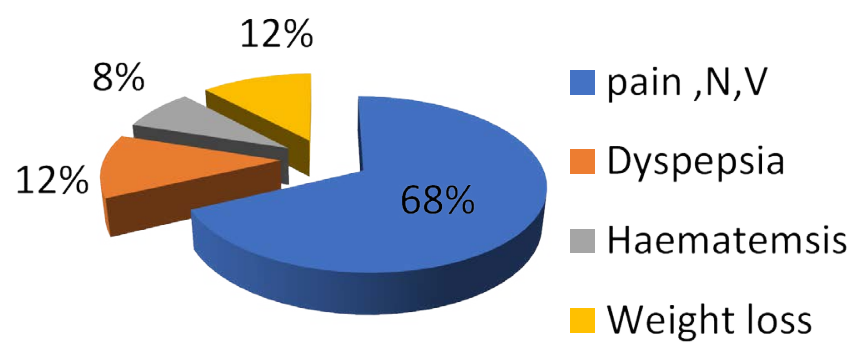

Figure 2. Frequency of patients complains

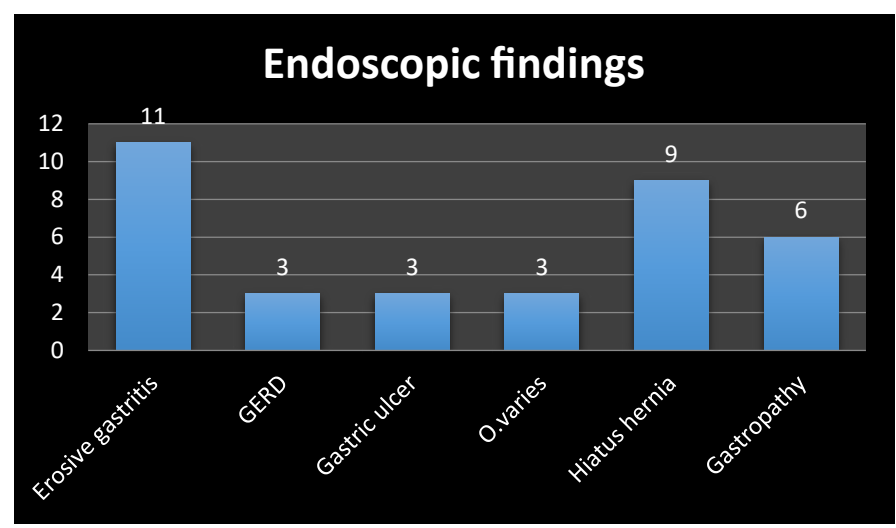

Figure 3. Frequency of endoscopic finding

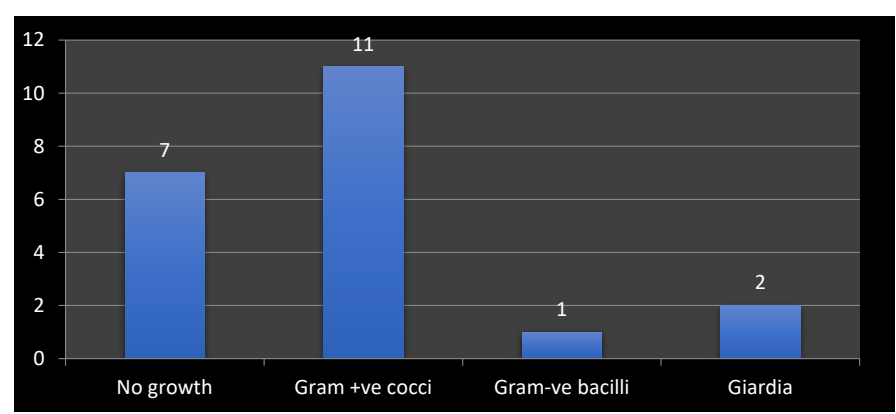

Figure 4. Frequency of microorganism detected by direct smear

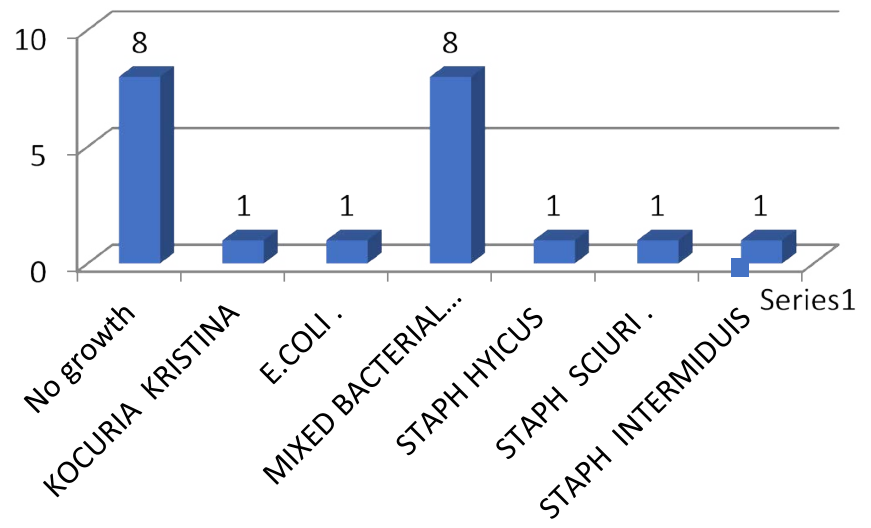

Figure 5. Frequency of microorganism detected by aerobic culture

containing only relatively low numbers of lactobacilli and other aciduric micro-organisms (101-102/ml of content), generally from the mouth. However, in some individuals, $\mathrm{H}$. pylori colonizes the gastric mucosa [14], and carriers may be symptomatic or non-symptomatic. A short residence time of about 1-2 h, gastric acid and nitric oxide, 
Table 1. The endoscopic versus histopathological findings

\begin{tabular}{|c|c|c|c|c|c|c|c|}
\hline \multicolumn{2}{|c|}{ Erosive gastritis } & \multirow{2}{*}{$\begin{array}{c}\text { GERD } \\
3\end{array}$} & \multirow{2}{*}{$\begin{array}{c}\text { Gastric ulcer } \\
1\end{array}$} & \multirow{2}{*}{$\begin{array}{l}\text { Oesoph- ageal } \\
\text { varies }\end{array}$} & \multirow{2}{*}{$\begin{array}{c}\text { Hiatus hernia } \\
1\end{array}$} & \multirow{2}{*}{$\begin{array}{c}\text { Gastropat hy } \\
2\end{array}$} & \multirow{2}{*}{$\begin{array}{r}\text { Total } \\
11\end{array}$} \\
\hline Chronic active gastritis & 4 & & & & & & \\
\hline Chronic atrophic changes & 1 & 1 & 1 & 1 & & 2 & 5 \\
\hline Erosions & 2 & 1 & & & & & 3 \\
\hline Lymphoid hyperplasia & & & & & & 2 & 2 \\
\hline Total & 7 & 3 & 2 & 1 & 3 & 5 & 21 \\
\hline
\end{tabular}

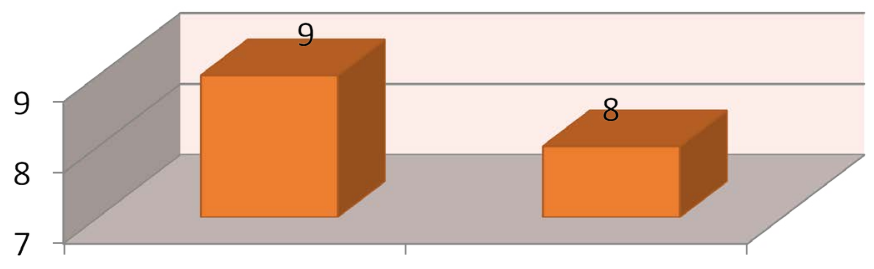

No growth

Mixed growth

Figure 6. Frequency of microorganism detected by anerobic culture

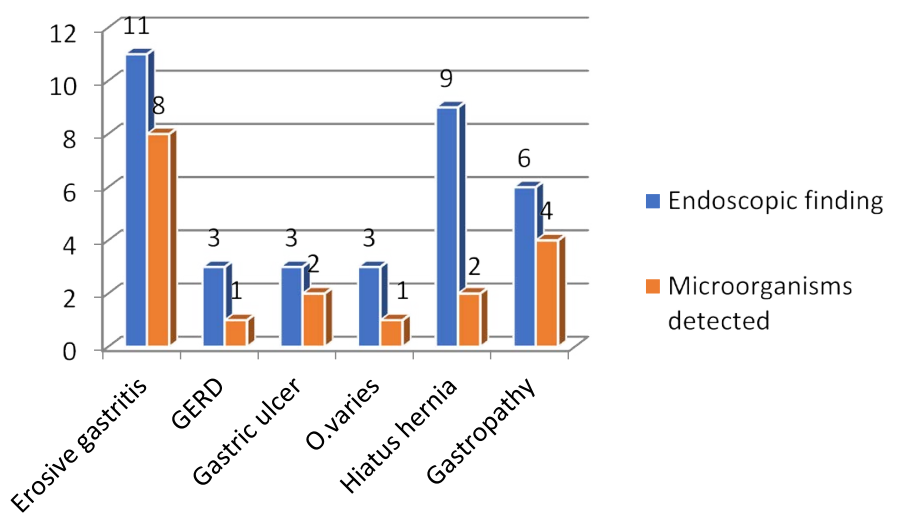

Figure 7. Frequency of endoscopic finding and microorganism detected
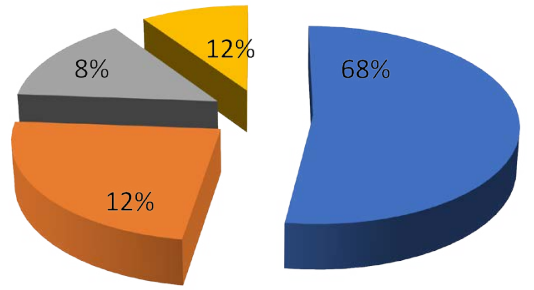

chronic active gastritis

chronic atrophic changes

erosion

Lymphiod hyperplasia

Figure 8. Frequency of histopathological finding

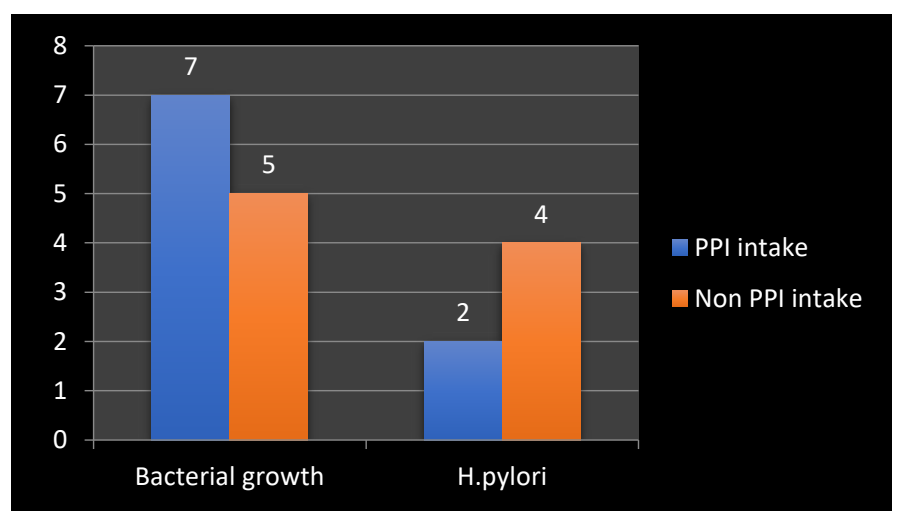

Figure 9. Frequency of bacterial growth and Helicobacter pylori with proton pump inhibitor drugs intake which arises from bacterial reduction of salivary nitrate, are the main factors preventing significant microbial growth in the stomach. Studies have shown that a $\mathrm{pH}$ of lower than 4 is effective in limiting the growth of bacteria [15].

In a hospital milieu, additional enteral bacteriae and yeasts can occur as a consequence of antibiotic therapy. Together with swallowed food, these bacteriae and the microbes that are contained in the food reach the stomach, and under physiologic conditions, they leave the stomach within a few hours. Only the acid resisting mycobacteriae can be found in the stomach's fasting secretion [14].

Helicobacter pylori is a spiral Gram-negative bacterium which was discovered by Marshall and Warren in 1982. Studies have indicated that the presence of $\mathrm{H}$. pylori is associated with a variety of gastrointestinal diseases including gastritis, duodenal and gastric ulcers, non-ulcer dyspepsia, and gastric adenocarcinoma and lymphoma [16].

The removal of the organism by antimicrobial therapy is correlated with the resolution of symptoms and cure of diseases [17].

In this study we identify microorganisms in upper gastrointestinal tract endoscopy and its relationship with the endoscopic and histopathological finding.

Our study was carried on 21 patients submitted to upper endoscopic examination for many complains with exclusion of patient with massive upper GIT bleeding as well as patients receiving antibiotic therapy in the last two weeks of endoscopy. The endoscopic samples including: Gastric wash for detection of microorganisms and its types by culture and gram stain. Gastric biopsy for detection of pathological mucosal changes associated with the presence of pathological microorganisms. Histopathology is usually considered to be the gold standard in the direct detection of $\mathrm{H}$. pylori infection and is also the first method used for the detection of $\mathrm{H}$. pylori. However, several factors influence the diagnostic accuracy of histology, such as site, size and number of biopsies, staining methods, proton pump inhibitor (PPI) intake, antibiotics and experience of the examining pathologist. Staining is the critical part of histopathological examination and several stains like routine H\&E staining, Giemsa and and immunohistochemically stains have been used to detect $\mathrm{H}$. pylori. Although immunohistochemical stain is the most sensitive and specific stain, $H \& E$ stain is usually sufficient for diagnosis of the degree of inflammatory cell infiltration, atrophy, and intestinal metaplasia. Caused by $\mathrm{H}$. pylori infection in routine clinical practice [18].

Giemsa stain is the preferred method in clinical practice because it is simple, highly sensitive for detection of the presence of $\mathrm{H}$. pylori and Giardia organism and less expensive [1].

Our results show that the tissue sections were also assessed for histologic features such as gastric mucosal changes for any evidence of gastritis, as chronic inflammation, presence of lymphoid follicles, metaplastic epithelial changes and glandular atrophy and presence or absence of H. pylori. The present study has several findings. Including 
endoscopic, microbial detection and histopathological finding as well as important clinical data as patient complains that collected from patient file sheets. First the patients complain including pain associated with nausea and vomiting represent $68 \%$, dyspepsia $12 \%$, haematemsis $8 \%$ and weight loss $12 \%$ as in Figure 2.

Second, the endoscopic finding including erosive gastritis $31 \%$, gastroesophageal reflux diseases (GERD) 9\%, gastric ulcer 9\%, esophageal varices $9 \%$, hiatus hernia $17 \%$ and gastropathy $25 \%$. The frequency of erosive gastritis, gastropathy and hiatus hernia respectively are higher than other finding as in Figure 3. Third the microorganism detected by direct smear are gram +ve cocci $52 \%$, gram -ve bacilli $5 \%$ and giardia $10 \%$ but $33 \%$ of cases have no growth. The frequency of gram $+v e$ cocci followed by giardia are higher than other gram -ve bacilli.

The finding of aerobic and anaerobic cultures was the higher frequency of mixed growth as well as detection of no growth in large number of cases. The relation between microorganisms in upper gastrointestinal tract endoscopy and different gastrointestinal diseases showed that microorganisms increases with erosive gastritis and gastropathy as in Figure 6. The histopathological finding showed the presence of Helicobacter pylori in number of cases with higher frequency of negative case.

We found direct relation between bacterial growth in gastric wash and proton pump inhibitor drug intake with higher frequency of increased bacterial growth with proton pump inhibitor drug intake but there is inverse relation between Helicobacter growth with PPI intake as there is higher growth with non-PPI intake and this may result from patchy bacterial colonization through the stomach and altered distribution because of gastritis with atrophy and intestinal metaplasia. So multiple gastric biopsies were recommended from different sites as in Figure 8.

\section{Conclusion}

The most frequent complaint of patient submitted for diagnostic upper endoscopy were epigastric pain and vomiting followed by dyspepsia. The frequent endoscopic finding was erosive gastritis and gastropathy. The frequent microorganism detected by cultures was mixed bacterial growth. So, there is a strong relationship between mixed bacterial growth that increased as a complication to PPI and chronic gastritis and gastropathy.

\section{References}

1. Eisen GM, Baron TH, Dominitz JA, Faigel DO, Goldstein JL, et al. (2002) Complications of upper GI endoscopy. Gastrointest Endosc 55: 784-793.
2. Kayaçetin S, Güreşçi S (2014) What is gastritis? What is gastropathy? How is it classified? Turk J Gastroenterol 25: 233-247. [Crossref]

3. Dupas JL, Fagniez PL, Palazzo L (2001) Diagnostic indications for upper gas Upper gastrointestinal endoscopy and gastrodoudenal disease in adults, excluding endoscopic ultrasonography and enteroscopy. ANAES/Guidelines department.

4. Ayoola AE, Ageely HM, Gadour MO, Pathak VP (2004) Prevalence of Helicobacter Pylori infection among patients with dyspepsia in south-western Saudi Arabia. Saudi Med J 25: 1433-1438.

5. Uemura N, Okamoto S, Yamamoto S, Matsumura N, Yamaguchi S, et al. (2001) Helicobacter pylori infection and the development of gastric cancer. N Engl J Med 345: 784-789. [Crossref]

6. Fallone CA, Barkum AN, Gottke MU, Best LM, Loo VG, et al. (2000) Association of Helicobacter pylori genotype with gastroesophageal reflux disease and other upper gastrointestinal disease. Am J Gastroenterol 95: 659-669.

7. Ayoola EA, Rashed RS, Mofleh IA, Faleh FZ, Laajam M (1996) Diagnostic yield of upper gastrointestinal endoscopy in relation to age and gender: a study of 10112 Saudi patients. Hepatogastroenterology 43: 409-415.

8. Morad NA, Ahmed M, Wabel A, Foli AK (1993) Helicobacter pylori associated dyspepsia in 208 patients from Southern Saudi Arabia. Annals of Saudi Medicine 13: 340-343.

9. Rowland M, Daly L, Vaughan M, Higgins A, Bourke B, et al. (2006) Age-specific incidence of Helicobacter pylori. Gastroenterology 130: 65-72. [Crossref]

10. Fox JG, Dangler CA, Taylor NS, King A, Koh TJ, et al. (1999) High-salt diet induces gastric epithelial hyperplasia and parietal cell loss, and enhances Helicobacter pylori colonization in C57BL/6 mice. Cancer Res 59: 4823-4828. [Crossref]

11. Lee SA, Kang D, Shim KN, Choe JW, Hong WS, et al. (2003) Effect of diet and Helicobacter pylori infection to the risk of early gastric cancer. J Epidemiol 13: 162168. [Crossref]

12. Machida-Montani A, Sasazuki S, Inoue M, Natsukawa S, Shaura K, et al. (2004) Association of Helicobacter pylori infection and environmental factors in non-cardia gastric cancer in Japan. Gastric Cancer 7: 46-53. [Crossref]

13. Schassan HH (2000) Bakteriologie des vagotomiertenMagens. In: Schumpelick V, Begemann F, Werner B: eds. Refluxkrankheit des Magens, 1 ed. Stuttgart: Enke.

14. Williams C (2001) Occurrence and significance of gastric colonization during acidinhibitory therapy. Best Pract Res Clin Gastroenterol 15: 511-521. [Crossref]

15. Macfarlane S, Dillon JF (2007) Microbial biofilms in the human gastrointestinal tract. J Appl Microbiol 102: 1187-1196. [Crossref]

16. Graham DY, Klein PD, Evans DG, Fiedorek SC, Evans DJ Jr, et al. (1992) Helicobacter pylori: Epidemiology, relationship to gastric cancer and the role of infants in transmission. Eur J Gastroenterol Hepatol 4: S1-S6.

17. Kumar M, Yachha SK, Aggarwal R, Shukla S, Pandey R, et al. (1996) Healing of chronic antral gastritis: effect of sucralfate and colloidal bismuth subcitrate. Indian $J$ Gastroenterol 15: 90-93. [Crossref]

18. Wotherspoon A, Ortiz-Hidalgo C, Falzon MR, Isaacson PG (1991) Helicobacter pylori associated gastritis and primary B Cell Lymphoma. Lancet 338: 1175-1176.

Copyright: (C2017 Ismail KA. This is an open-access article distributed under the terms of the Creative Commons Attribution License, which permits unrestricted use, distribution, and reproduction in any medium, provided the original author and source are credited. 